\title{
The Effect of Backfill Grout Hardening on Impact-Echo Signal - Numerical Analysis
}

\author{
Ju-Young Choi ${ }^{1}$, Kyung-Yul Kim² ${ }^{2}$ Ki-Il Song ${ }^{3}$ \\ ${ }^{1}$ Inha University \\ Inha-ro 100, Nam-gu, Incheon, Korea \\ brclud@naver.com \\ ${ }^{2}$ Korea Electric Power Research Institute \\ Munji-ro 105, Yuseong-gu, Deajeon, Korea \\ ksong@inha.ac.kr
}

\begin{abstract}
The aim of this study is to analyse the Impact-Echo (IE) signal characteristic of backfill grout in shield TBM during hardening. IE test on simplified 2-layer model (e.g., segment and grout layer) is simulated by using Finite Element Method (FEM) software. Three different hardening state of backfill grout were selected and simulated. Time domain signal obtained from IE test were analysed with Fast-Fourier Transformation (FFT) and Short Time Fourier Transformation (STFT). As the backfill grout hardens, damping ratio increases and resonance duration decreases. This result can be the basis for the derivation of thickness of two-layer system composed with segment and backfill grout during hardening process.
\end{abstract}

Keywords: TBM tunnel, backfill grout, Impact-Echo, Fast-Fourier Transform, Finite Element Method, Short Time Fourier Transform

\section{Introduction}

During TBM tunnel excavation, backfill grout should be injected after the installation of segment lining to ensure the stability of the tunnel and to minimize ground deformation. During tunnelling, volume of backfill grout and injection pressure is monitored to control the quality of backfill grout. However, the quality of backfill grouting has not been evaluated after the injection. Moreover, the properties of backfill grout change after the injection due to hardening. In this study, Impact-Echo (IE) is adopted to evaluate the quality of backfill grouting. The effect of backfill grout hardening on Impact-Echo signal is investigated with numerical analysis.

\section{Optimization of numerical model}

FEM software (ABAQUS Ver. 6.5) is used to simulate IE test for 2-layer composed with segment lining and backfill grout. Axisymmetric model is adopted as shown in Fig. 1. To avoid the reflection at the side of the model, infinite element is used for the right side of the numerical model. The dimension of finite element is determined as $1 \mathrm{~cm}$ by $1 \mathrm{~cm}$ considering the equation proposed by Zerwer (2002). Time increment should satisfy the spatial Nyquist limit (Eq. (1)) and temporal Nyquist limit (Eq. (2)). In this study, $1 \mu$ s of time increment is derived.

$$
\begin{gathered}
\frac{\Delta x}{10 \cdot V_{p}} \leq \Delta t \leq \frac{\Delta x}{V_{p}} \\
\Delta t \leq \frac{1}{2 \cdot f_{\max }}
\end{gathered}
$$

After the injection, the properties of backfill grout changes depending on the time: the stiffness increases and damping ratio decreases. According to Hardin and Drnevich (1972), shear modulus and damping ratio have inverse proportion. In 
this study, Free-Free Resonant Column (FFRC) test is performed for obtaining the parameter of backfill grout depending on the curing time. The bentonite-cement grout is mixed with sodium silicate. Volumetric content of sodium silicate is $5 \%$ in this study. Three different curing stages were selected to consider the time-dependent hardening behaviour of backfill grout (Fig. 2) and the corresponding parameters are tabulated in Table 1.

In IE test, steel ball is used to generate the stress wave on the surface of segment. When the density and diameter of steel ball are $7850 \mathrm{~kg} / \mathrm{m}^{3}$ and $15 \mathrm{~mm}$ diameter and it drops from $1 \mathrm{~m}$ above on the concrete segment lining, the contact time and force are $64 \mu \mathrm{s}$ and $0.17 \mathrm{~N}$ from the equation proposed by Sansalone \& Carino (1986), respectively. Acceleration in vertical direction is monitored at $6 \mathrm{~cm}$ apart from the impact point.

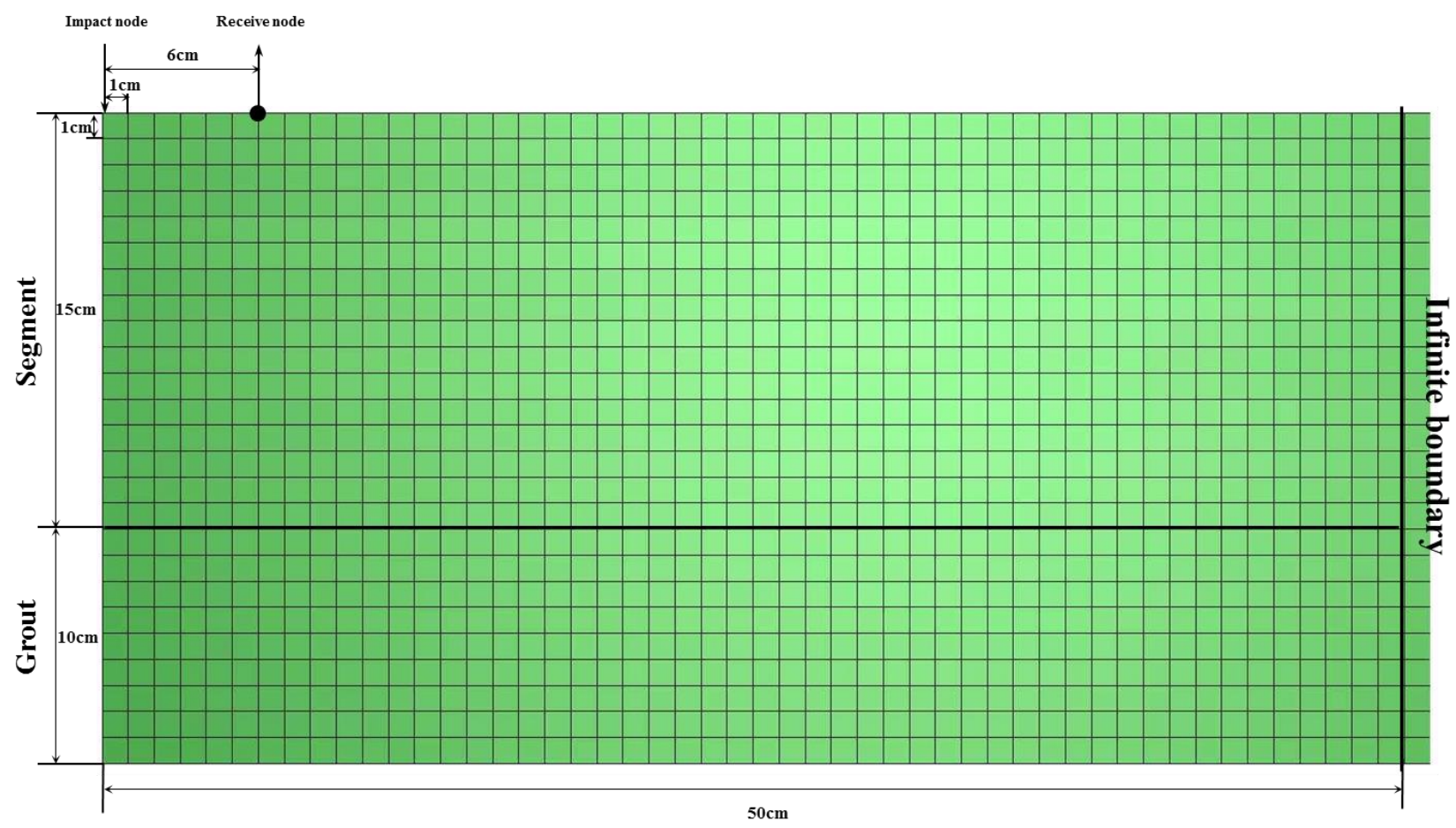

Fig. 1: 2-layer model composed with segment lining and grout. 


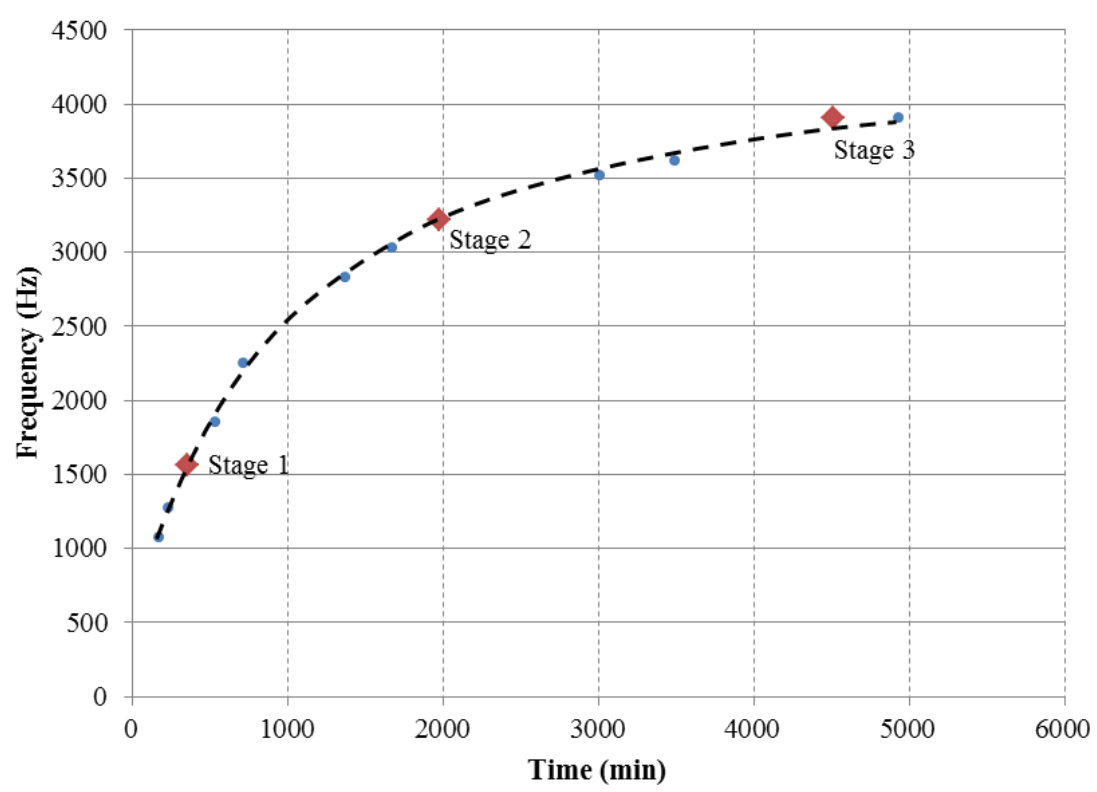

Fig. 2: Time VS resonance frequency by FFRC test.

Table 1: Input parameters for numerical analysis.

\begin{tabular}{|c|c|c|c|c|c|}
\hline Material & $\begin{array}{c}\text { Curing time } \\
(\mathrm{min})\end{array}$ & $\begin{array}{c}\text { Density } \\
(\text { assumed, } \\
\left.\mathrm{kg} / \mathrm{m}^{3}\right)\end{array}$ & $\begin{array}{c}\text { Elastic } \\
\text { modulus } \\
(\mathrm{Pa})\end{array}$ & Poisson's ratio & $\begin{array}{c}\text { Stiffness-proportional damping coefficient } \\
(\mathrm{sec})\end{array}$ \\
\hline Segment & - & 2400 & $3.50 \mathrm{E}+10$ & 0.2 & $1.00 \mathrm{E}-6$ \\
\hline Stage 1 & 360 & 1600 & $1.69 \mathrm{E}+08$ & 0.2 & $7.50 \mathrm{E}-6$ \\
\hline Stage 2 & 1980 & 1780 & $8.01 \mathrm{E}+08$ & 0.2 & $3.35 \mathrm{E}-6$ \\
\hline Stage 3 & 4520 & 2000 & $1.33 \mathrm{E}+09$ & 0.2 & $2.57 \mathrm{E}-6$ \\
\hline
\end{tabular}

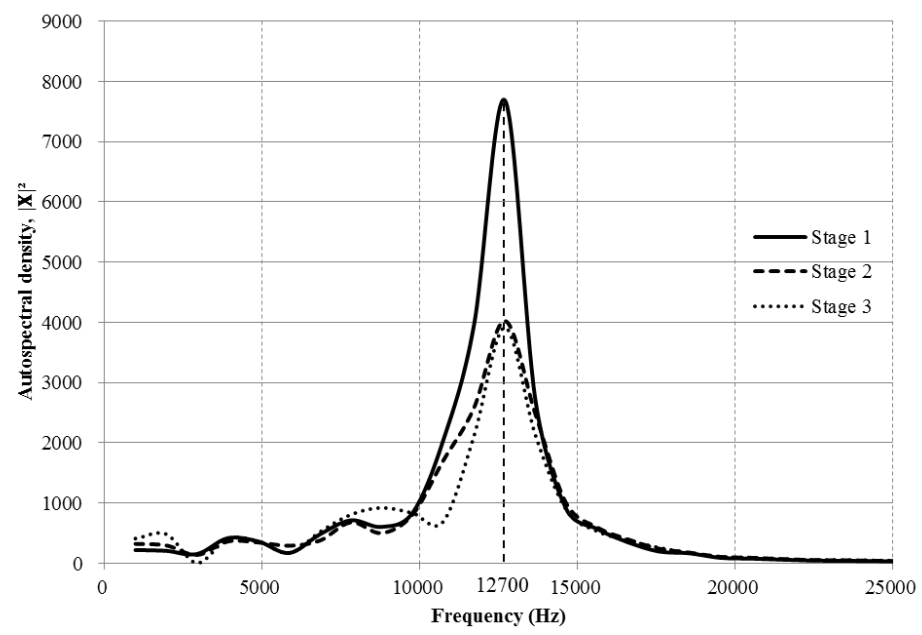

(a) Frequency domain response

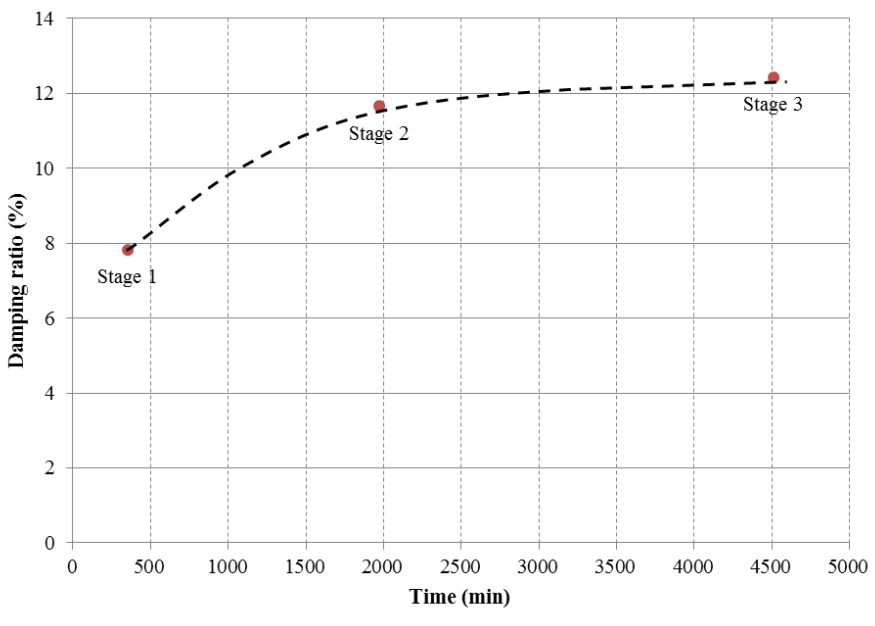

(b) Damping ratio

Fig. 3: Result of frequency analysis using FFT depending on curing time.

\section{Signal characteristics depending on backfill grout hardening}


IE test for two-layered system is simulated depending on the three different hardening stages. Time increment is $1 \mu$ s and the total analysis step is 2500 , until $0.0025 \mathrm{sec}$. Time domain signal is transformed into frequency domain by FFT and STFT. To obtain the multiple reflection of stress wave, surface wave which travels from impact point to monitoring point is omitted during signal processing.

Fig. 3 shows frequency response depending on the curing stage. Resonance frequency of IE signal is $12700 \mathrm{~Hz}$ and does not change depending on the curing stage. However, frequency response and geometric damping ratio is significantly affected by curing process. In stage 1, the maximum autospectral density is 7687 and geometric damping ratio is $7.811 \%$. In stage 2 , the maximum autospectral density is getting smaller and geometric damping ratio increases to $11.644 \%$. When the backfill grout is fully cured, the maximum autospectral density decreases to 3914 and geometric damping ratio increases to $12.417 \%$. It can be concluded that maximum autospectral density decreases and geometric damping ratio increases as the backfill grout hardens.

The results of IE simulation were transformed to time-frequency domain by STFT and presented in Fig. 4. If we take a width of the contour line from the normalized time-frequency response as resonance duration, $T_{R}$, it is about $0.50 \mathrm{~ms}$ in case of stage 1 . Resonance duration, $T_{R}$, is $0.39 \mathrm{~ms}$ for stage 2 and $0.35 \mathrm{~ms}$ for stage 3 . The resonance duration decreases as the backfill grout hardens as it is presented in Fig. 5. By combining the results from FFT and STFT, transmission of stress wave increases and energy dissipation increases as the backfill grout hardens.

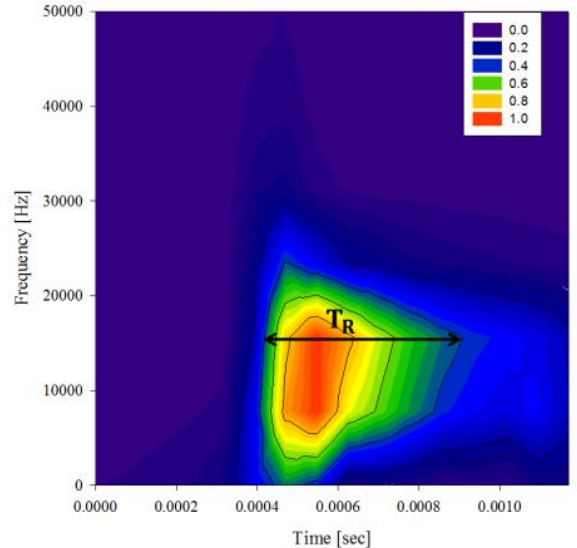

(a) Stage 1

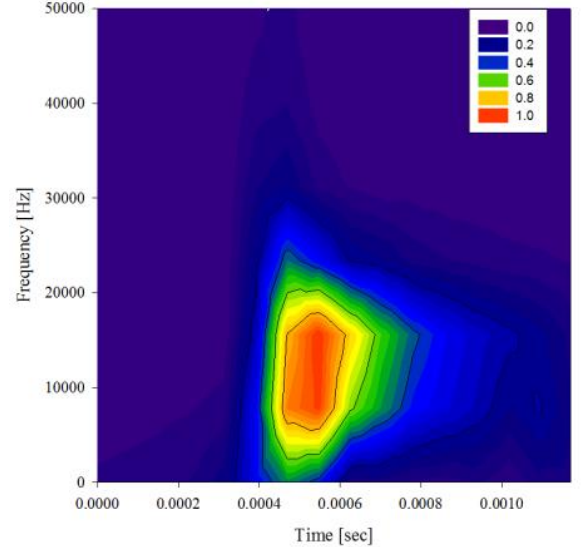

(b) Stage 2

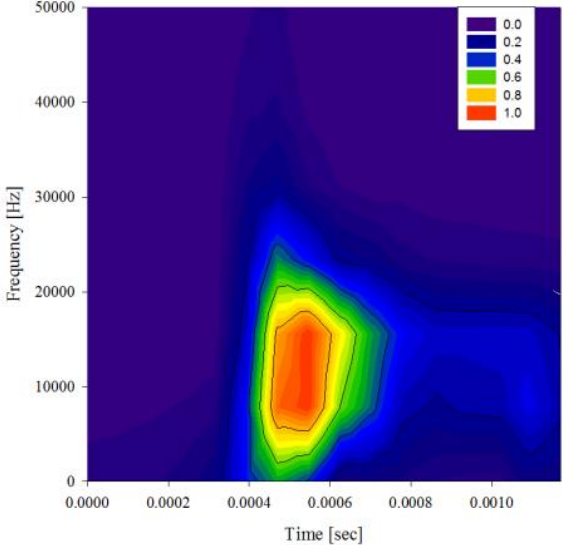

(c) Stage 3

Fig. 4: Time-frequency analysis using STFT. 


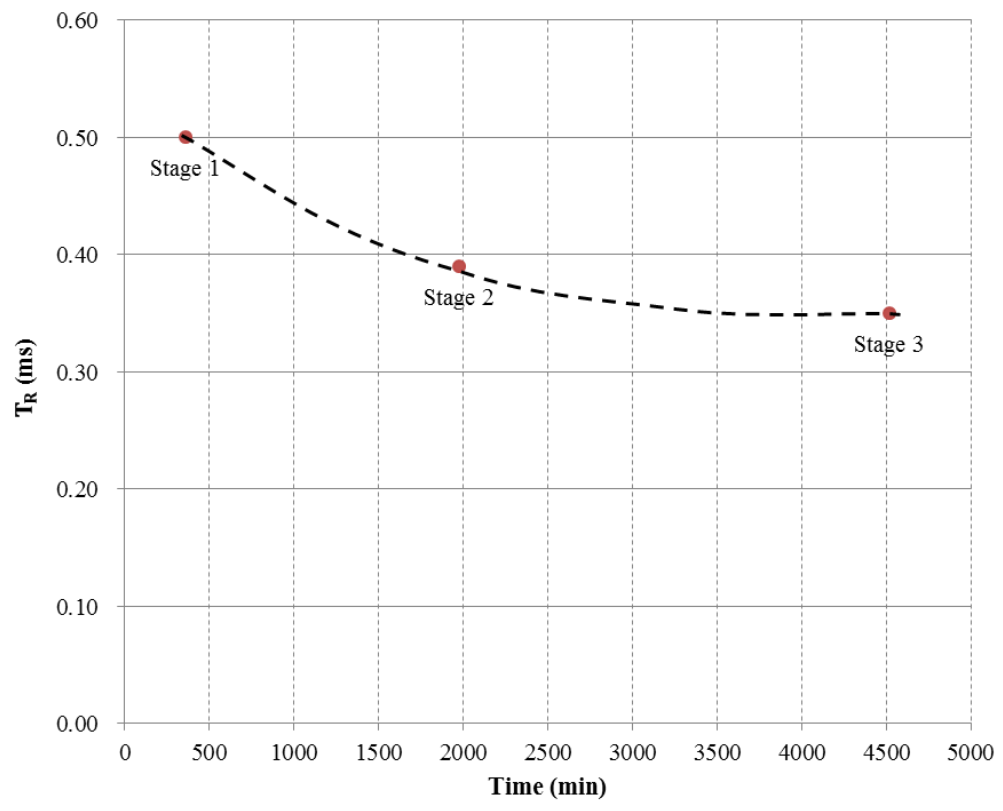

Fig. 5: Resonance duration during the grout curing time.

\section{Conclusion}

This study is a numerical analysis on the effect of backfill grout hardening on Impact-Echo signal. IE test on simplified two-layered model (e.g., segment and grout layer) is simulated by using Finite Element Method (FEM) software. Three different hardening stages were selected and its material properties are obtained through FFRC test. Time domain signal obtained from IE test for three different hardening stages were analysed with FFT and STFT. From the frequency response, it is found that autospectral density decreases and geometric damping ratio increases as the backfill grout hardens. From the time-frequency response, it is found that resonance duration decreases as the backfill grout hardens. It implies that transmission of stress wave increases and energy dissipation increases as the backfill grout hardens. This result can be the basis for the derivation of thickness of two-layer system composed with segment and backfill grout during hardening process.

\section{Acknowledgements}

This study is supported by research project funded by Korea Electric Power Research Institute.

\section{References}

[1] B. O. Hardin, V. P. Drnevich, "Shear modulus and damping in soils: Design equations and curves," Journal of SMFE, vol. 98, no. SM7, pp. 667-692, 1972.

[2] K. I. Song and G. C. Cho, "Bonding state evaluation of tunnel shotcrete applied onto hard rocks using the impactecho method," NDT\&E International, vol. 42, no. 6, pp. 487-500, 2009.

[3] M. Sansalone, N. J. Carino, Impact-Echo: a method for flaw detection in concrete using transient stress waves. National Bureau of Standards, 1986.

[4] M. Sansalone, W. B. Streett, Impact-Echo: Nondestructive Evaluation of Concrete and Masonry. Bullbrier Press, 1997.

[5] A. Zerwer, G. Cascante, J. Hutchinson, "Parameter estimation infinite element simulations of Rayleigh waves," Journal of geotechnical and geoenvironmental engineering, vol.128, no. 3, pp. 250-261, 2002.

[6] N. J. Carino, "Impact Echo: The Fundamentals," International Symposium on Non-Destructive Testing in Civil Engineering, 2015. 